\title{
Voltage Spectral Structure as a Parameter of System Technical Diagnostics of Ship Diesel Engine-Synchronous Generators
}

\author{
Aleksandrs Gasparjans (Researcher, Maritime Academy of Latvia), \\ Aleksandrs Terebkovs (Researcher, Maritime Academy of Latvia), \\ Anastasia Zhiravetska (Professor, Riga Technical University)
}

\begin{abstract}
A method of technical diagnostics of ship diesel engine - generator installation - is proposed. Spectral-power diagnostic parameters of the synchronous generator voltage and currents are used. The electric machine in this case is the multipurpose sensor of diagnostic parameters. A judgment on the quality of the operational processes in diesel engine cylinders and its technical condition is possible on the basis of these parameters. This method is applicable to piston compressor installations with electric drive. On the basis of such parameters as rotating torque, angular speed and angular acceleration it is possible to estimate the quality of the operating process in the cylinders of a diesel engine, the condition of its cylinder-piston group and the crank gear mechanism. The investigation was realized on the basis of a diesel-generator with linear load. The generator operation was considered for the case of constant RL load. Together with the above mentioned, the condition of bearings of synchronous machines, uniformity of the air gap, windings of the electric machine were estimated during the experiments as well. The frequency spectrum of the stator current of the generator was researched and analyzed. In this case the synchronous machine is becoming a rather exact multipurpose diagnostic sensor. The signal of nonuniformity in the operation process of diesel engine cylinders and its technical condition is the increasing of the amplitudes of typical frequencies.
\end{abstract}

Keywords - Diesel engines; Generators; Torque measurement; Vibration measurement.

\section{INTRODUCTION}

Nowadays in approximately $80 \%$ of cases diesel-generators are applied in ship installations as the main and emergency sources of electric power. The questions of the diesel technical diagnostics are in details considered in [1]-[4], [13]. In the present paper the authors propose a complex approach to the technical diagnostics of electro-mechanical system "dieselgenerator". Together with its basic purpose - electric energy generation - the synchronous electric generator is used as a multifunctional sensor of the diagnostic information. The shaft of the generator is rigidly fixed with the crankshaft of the diesel. All the operational processes influence the electromagnetic processes of the generator. The changing of the parameters of the electromagnetic processes makes an impact on those of the diesel operational process. In the paper the method of technical diagnostics of diesel-power installations is considered where the output voltage and current are used as diagnostic parameters for spectral-power characteristics of the higher harmonics and sub-harmonics. With the rapid development of means of measurement the storage and processing of information are becoming possible including microprocessor techniques. Earlier more often the harmonics of voltage and current of 5-7 orders were applied for such analysis. The harmonics of higher orders usually were not considered because of their insignificant size and difficulty of measurement. Occurrence of modern high-speed analog-digital converters allows to measure spectral-power characteristics of higher harmonic components - up to $11 \ldots 15$-th with the amplitude of $2 \% \ldots$ $0.2 \%$ from that of the basic harmonic. Application of mathematical methods allows revealing a place and reason of their occurrence. Thus, spectral-power characteristics of higher harmonics can be accepted as diagnostic parameters as well as the sub-harmonics can be used with these purposes. The comparison of parameters of the harmonics of different order with reference values allows expanding opportunities of technical diagnostics systems. The harmonic components are a product of electromagnetic interaction of electric machine rotor and stator. The character of this interaction depends not only on the parameters of the electric machine, but also on the mechanical characteristics of the drive engine - its instantaneous angular frequency and angular acceleration. These parameters characterize the technical condition of a drive engine.

Non-uniformity of the rotating torque, instantaneous fluctuations of angular speed and angular frequency result in parameter variations of electromagnetic processes in generator. Thus, the spectral structure of the output currents and voltages is changing. In the given paper the method of technical diagnostics based on continuous control of non-uniformity of the diesel engine rotating torque, fluctuations of instantaneous angular speed and angular acceleration for one-two turn of a diesel engine crankshaft is suggested. The obtained data are compared either with reference values, or with the values received as a result of mathematical modeling. Deviations of these non-uniformity parameters from reference characterize the condition of the diesel engine cylinder-piston group and quality of the operation process in its cylinders. The second feature of this method is used as the multipurpose sensor of the regular generator in a diesel engine-electric installation. 


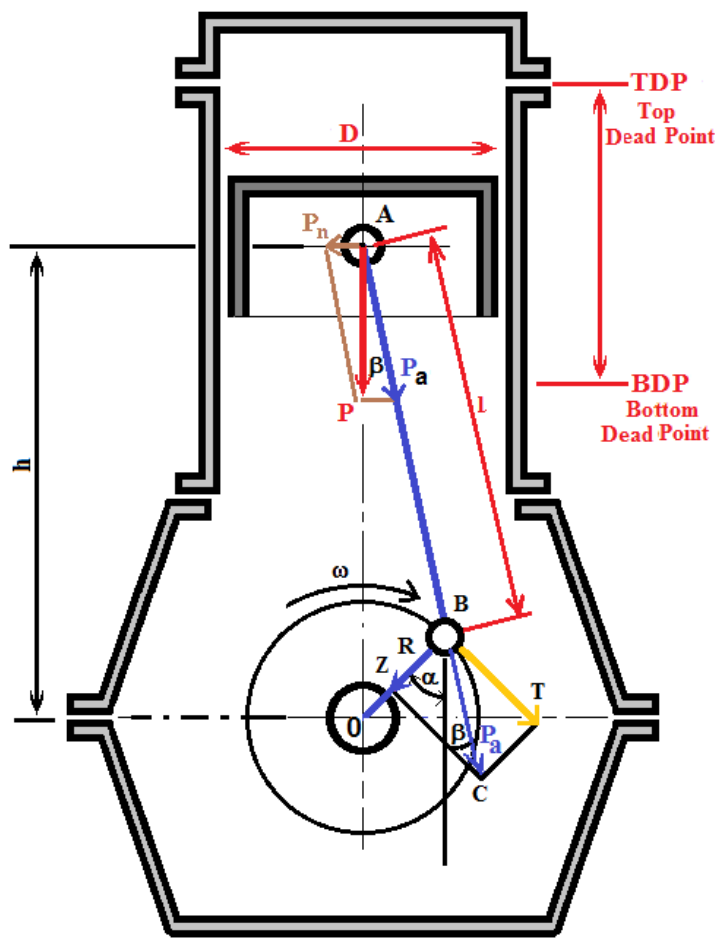

Fig. 1. Forces of pressure. Transposition of the piston is accompanied by impact on the walls of the cylinder, increasing deterioration of the cylinder liner and causing additional noise (vibration).

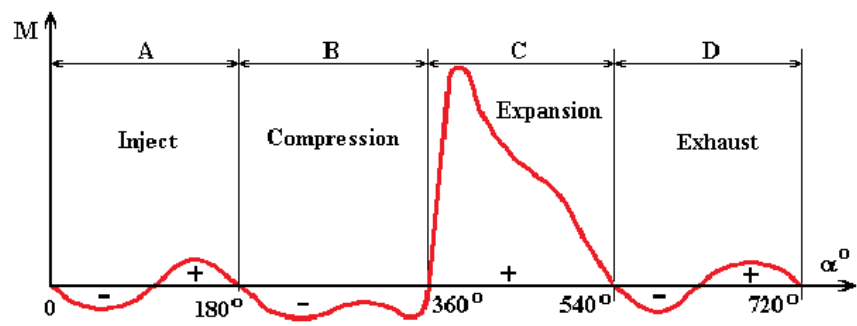

Fig. 2. The diagram of the rotating torque

\section{SHIP DIESEL ENGINE-GENERATOR PARAMETERS FOR TECHNICAL DIAGNOSTICS}

The force of pressure of burning gases $P$ (Fig. 1) is directed along the axis of the cylinder downwards to the crankshaft [5], [6]. This force $P$ by rules of a parallelogram can be spread out on two aspects - force $P_{a}$ operating along the axis of the rod and cross-section force $P_{n}$, directed perpendicularly to the axis of the cylinder.

Force $P_{n}$ causes a single action pressing the piston to the cylinder, an increase in forces of friction and deterioration of rubbing details. At the stage of compression this force is directed to the opposite part. This force (perpendicular axes of the cylinder), being the top dead point (TDP), shifts the piston from one wall of the cylinder. Force $P_{n}$ can be defined as

$$
P_{n}=P \operatorname{tg} \beta \text {. }
$$

Force $P_{a}$, directed along the axis of the rod, is presented as

$$
P_{a}=P / \cos \beta \text {. }
$$

Force $P_{a}$ can be transferred along the connecting rod in the direction of its action from point $\mathrm{A}$ (the center of the piston pin) to point $\mathrm{B}$ - the point of connection of the connecting rod and a crank. Force $P_{a}$ can be divided into two components: the radial force $Z$ directed to the center of the axis of rotation of crankshaft and tangent force $T$, operating perpendicularly to the radius of the crank. The angle between forces $P_{a}$ and $Z$ will be equal to both $\alpha+\beta$. The tangent force $T$ is equal to

$$
T=P_{a} \sin (\alpha+\beta) .
$$

Having replaced the force $P_{a}$ expression (2), we obtain

$$
T=P \sin (\alpha+\beta) / \cos \beta \text {. }
$$

The force $T$ creates a rotating torque $M$ with arm of force, equal to radius of the crank $R$

$$
M=T R .
$$

The radial force $Z$ acting on the bearings of the crankshaft is detrimental. Its value can be defined as

$$
\begin{gathered}
Z=P_{a} \cos (\alpha+\beta), \\
\text { or } Z=P \cos (\alpha+\beta) / \cos \beta .
\end{gathered}
$$

The tangent force $T$ is a variable. Its size is equal to zero at top dead point (TDP) and bottom dead point (BDP) of the piston. At these points force $P_{a}$ is directed precisely to the radius of the crank and along the axis of the cylinder. The arm of the force is also equal to zero. Hence, the rotating torque at these points is zero. Crank gear, like to the converter of back and forth motion in rotary, is distinctive of the non-uniform rotating torque. It is necessary to consider, that the value of force $P$ in the process of direction of the piston downwards also does not remain constant. Fig. 2 demonstrates the diagram of the rotating torque according to the angle of the turn of crankshaft $\alpha$.

During the stage of inject and exhaust the rotating torque of $M$ has a sign-variable character and defines the torque of inertia forces. At this time the pressure of gases in the cylinder can be neglected. During the step of compression the tangent force $T$ is negative and the force from the pressure of gas increases, remaining positive. In the multicylinder engine the rotating torques from different cylinders sum up and the total rotating torque $\Sigma M$ is becoming more uniform. During rotation the total rotating torque $\Sigma M$ overcomes the torque of resistance $M_{S}$ of the forces of friction, inertia, magnetic field of the generator. During the operation the total torque $\Sigma M$ can be either higher or lower than the torque of resistance $M_{s}$ (Fig. 3). Hence, the angular speed of crankshaft rotation will not be a constant. At $\Sigma M>M_{s}$ the angular speed $\omega$ will increase, at $\Sigma M<M_{s}$ it will decrease. With the changing of angular speed, the angular acceleration of the crankshaft will also be changed. 


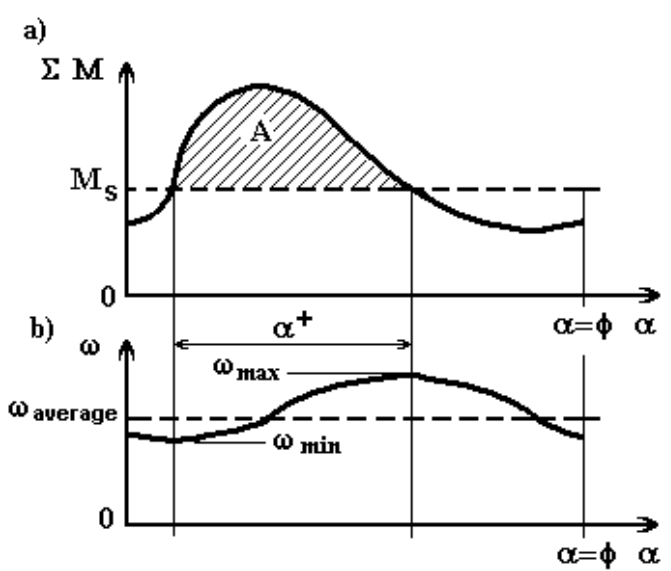

Fig. 3. Angular speed (b) and the torque (a) of the generator diagrams.

A degree of non-uniformity of angular speed is characterized with the factor:

$$
\sigma=\left(\omega_{\max }-\omega_{\min }\right) / \omega_{\text {average }} .
$$

Working on the rowing screw the degree of non-uniformity $\sigma$ is supposed as $\sigma=1 / 20 \ldots 1 / 40$; working on the generator of direct current it is $\sigma=1 / 100 \ldots 1 / 150$, but on the alternating current generator $\sigma=1 / 150 \ldots 1 / 200$ [3], [4]. These changes of the rotating torque, angular speed and angular torque lead to fluctuations of the magnetic flow vector in the generator. As diagnostic parameters of the total rotating torque change, angular speed and angular acceleration for one or several turns of the crankshaft of the engine are chosen.

In the setting process of the synchronous machine (the voltage of network $U$ and excitation current $I_{f}$ do not change) to each external torque $M_{\text {out }}$ a certain position of the rotor magnetic axis is in relation to the vector of the total magnetic field [7]-[10]. This position is characterized by the angle $\theta$, which is corresponded to the external torque $M_{\text {out }}=M_{0}$ on the angular characteristic of the synchronous machine (Fig. 4, Point 1), for the diesel engine $M_{\text {out }}$ is the torque of loading $M_{s}$. At a constant electric loading of the generator and change of rotating torque $M_{\text {out }}$ on both $\Delta M$ leads to the changing of the angle $\theta$ to $\alpha$, which is reached not at once, but after transient (Fig. 4, Point 2). The angular speed of the synchronous machine rotor and the crankshaft of the diesel engine will increase with acceleration $\frac{d \omega}{d t}=\frac{\Delta M_{\text {out }}}{J}$, where $J$ is the moment of inertia of rotating parts of the electric machine and diesel engine. The increase in angular speed of the rotor and of the diesel engine crankshaft, and also the increase of angle $\theta$ both $\theta=\theta+\alpha$ will take place before the new moment of balancing (Fig. 4, Point 2) [11]-[15]. At this point the electromagnetic torque $M$ will be equal to the rotating torque of the diesel engine $M_{\text {out }}$.

However, in the case of rotation of the synchronous machine by a diesel engine with the non-uniform rotating torque and non-uniform angular frequency (Fig. 2) this transitive process will not have time to end completely and will be periodically repeated with each turn of the crankshaft. In this case the rotating torque of the diesel engine contains the constant component $M_{\text {out } 0}$ and harmonic components $M_{\text {out }}$ :

$$
M_{\text {out }}=M_{\text {out } 0}+\sum_{v} M_{\text {out vm }} \cos \left(v \omega t+\varphi_{v}\right) .
$$

At rotating torque $M_{\text {out }}$ the angle $\theta$ also will change in size for value $\Delta \theta$ (Fig. 4), which can be presented in the form of Fourier series [7]:

$$
\Delta \Theta=\sum_{v} \Delta \Theta_{v}=\sum_{v} \Delta \Theta_{v m} \cos \left(v \omega t+\zeta_{v}\right) .
$$

Similarly by means of Fourier series it is possible to express the flux linkage values both $\Delta \psi_{d}$ and $\Delta \psi_{q}$ along the $d$ and $q$ axes of the synchronous machine and the corresponding currents $\Delta i_{d}, \Delta i_{q}$ :

$$
\Delta i_{d}=\sum_{v} \Delta i_{d v} \text { and } \Delta i_{q}=\sum_{v} \Delta i_{q v}
$$

where

$$
\begin{aligned}
& \Delta i_{d v}=\operatorname{Re}\left(\Delta i_{d v}\right)=\operatorname{Re} \frac{\Delta \Psi_{d v}}{x_{d}(j v \omega)}=-U \sin \Theta_{0} \operatorname{Re} \frac{\Delta \dot{\Theta}}{x_{d}(j v \omega)}, \\
& \Delta i_{q v}=\operatorname{Re}\left(\Delta i_{q v}\right)=\operatorname{Re} \frac{\Delta \dot{\Psi}_{q v}}{x_{q}(j v \omega)}=U \cos \Theta_{0} \operatorname{Re} \frac{\Delta \dot{\Theta}}{x_{q}(j v \omega)},
\end{aligned}
$$

$v \quad$ number of harmonic;

$\omega \quad$ angular speed of the machine.

The specified harmonic components of the rotating torque can not only sum up, but also be subtracted.

The increment of the electromagnetic torque will be equal to

$$
\Delta M_{\text {emag }}=\sum_{v} \Delta M_{\text {emag } v} .
$$

The equation of the synchronous machine rotor movement for small angle $\theta$ fluctuations at sudden change of the external rotating torque $\Delta M_{\text {out }}$ looks as follows:

$$
M_{\text {out }}-M_{\text {emag }}+M_{a s}=J \frac{d \omega}{d t} .
$$

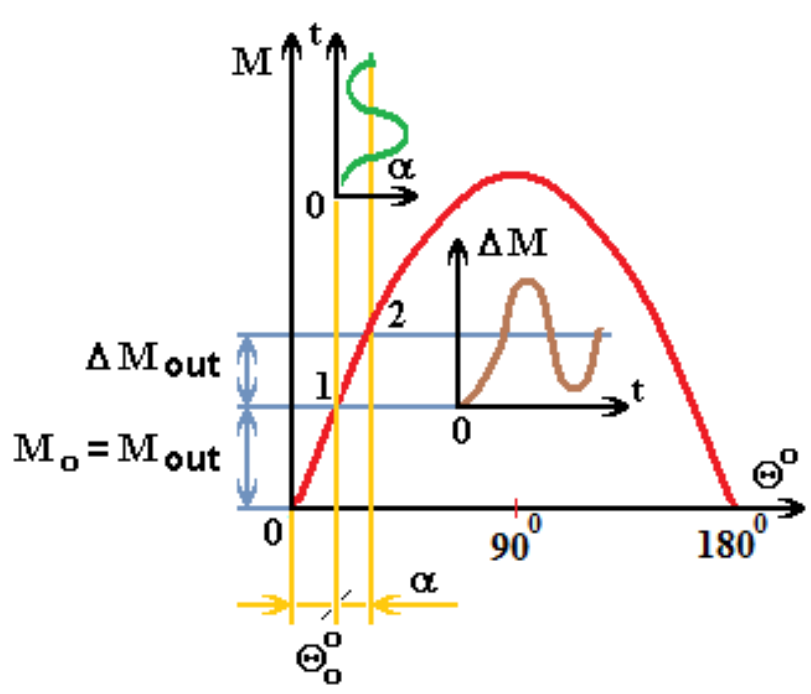

Fig. 4. Angular characteristic of the synchronous machine. 
In (15) $M_{\text {out }}$ is the external rotating torque.

In turn, $M_{\text {emag }}$ is the synchronous electromagnetic torque at angle $\theta=\theta_{0}+\alpha$ equal to $M_{0}+\Delta M=M_{0}+M_{\text {syn }} \alpha$.

$M_{0}=f\left(\theta_{0}\right)$ is the torque at $\theta=\theta_{0}$ under the angular characteristic (Fig. 4).

The specific synchronizing torque at both $\theta=\theta_{0}$ is found as

$$
M_{s y n}=\left(\frac{\partial M}{\partial \theta}\right)_{\theta=\theta_{0}} \text {. }
$$

$M_{a s}$ - the asynchronous electromagnetic torque from the interaction of currents induced in damper winding and the winding of excitation with a resulting magnetic field (with low slip) at a sudden change of the external rotating torque with both $\Delta M_{\text {out }}$, will be equal to

$$
\begin{gathered}
M_{a s}=M_{a s} s=-D \frac{d \alpha}{d t}, \\
\text { and } M_{a s}=\frac{m U^{2}}{\omega_{s y n} R_{2}^{\prime}}
\end{gathered}
$$

where

$$
\begin{array}{ll}
m & \text { the number of phases; } \\
D=\frac{M_{a s}}{\omega_{\text {syn }}} & \text { damper factor. }
\end{array}
$$

The specified changes of angle $\Delta \theta_{v}$ depending on the number of harmonics can achieve $6 \ldots 12$ degrees. The spectral structure of voltage and currents of the synchronous generator strongly depends on operating modes of the ship network. In this case a combination of specified factors worsening electromagnetic conditions on the vessel probably takes place.

The movement of a rotor at its fluctuations can be described, having expressed all necessary sizes through the initial position of rotor angle $\theta_{0}$ and its small angle deviation $\Delta \theta_{0}=\alpha$. The angle $\theta_{0}$ (between vector $E_{f}$ and vector voltage $U$ ) rotating with angular speed $\omega_{s y n}=2 \pi f$ is shown in Fig. 5 .

The electric angular speed of the rotor will be equal to the angular synchronous speed $\omega_{\text {syn }}$ and the additional angular speed connected with additional change of angle $\theta$.

$$
\omega=\omega_{s y n}+\frac{d \Theta}{d t}=\omega_{s y n}+\frac{d \alpha}{d t}
$$

The angular speed of the rotor will be equal to

$$
\omega=\omega_{\text {syn }}+\frac{d \alpha}{p d t},
$$

where $p$ is the number of pole pairs, but the acceleration of the rotor can be defined as

$$
\frac{d \omega}{d t}=\frac{d^{2} \alpha}{p d t^{2}} .
$$

The rotor slip

$$
s=\frac{\omega_{s y n}-\omega}{\omega_{s y n}}=-\frac{d \alpha}{\omega_{s y n} d t} .
$$

The equation of the movement of the rotor (15), is expressed through the angle $\alpha$ and its derivatives. It will be described by the linear non-uniform differential equation of the second order with constant factors:

$$
\frac{d^{2} \alpha}{d t^{2}}+\frac{D p}{J} * \frac{d \alpha}{d t}+\frac{M_{\text {syn }} p}{J} \alpha=\frac{p}{J} M_{\text {outv }} * \cos \omega_{v} t .
$$

Fluctuations of angle $\theta$ are accompanied by fluctuations of the electromagnetic torque $M_{\text {emag }}$ (Fig. 5), angular acceleration $\varepsilon$ and angular rotation frequency $\omega$.

Fluctuations of the electromagnetic torque $M_{\text {emag }}$ cause the fluctuations of active capacity $P=\omega \Delta M$ and also fluctuations of rms value and phase of current. It is possible to find the rms value of the current from the vector diagram of the synchronous machine (Fig. 5)

$$
I=\frac{\sqrt{E_{f}^{2}+U^{2}-2 U E_{f} \cos \Theta}}{X_{l}} .
$$

The specified changes of the rotating torque, angular frequency and angular acceleration can be defined by means of analysis of an instantaneous voltage of the generator or defining the actual position of the main magnetic flow vector of the generator placing the Hall sensors in the air gap of magnetic circuit. In this case the synchronous machine is becoming a rather exact multipurpose diagnostic sensor.

\section{EXPERIMENTAL RESULTS}

For the purposes of technical diagnostics the diesel engineelectric unit represents the greatest interest for the analysis of the specified fluctuations of the rotating torque, angular speed and angular acceleration.

On the basis of these parameters it is possible to estimate the quality of the operating process in the cylinders of a diesel engine, the condition of its cylinder-piston group and crank gear mechanism. In this case it is necessary to supply the diagnostic system with signals from the sensor of the top dead point (TDP) of the first cylinder and the sensor of angular position of the crankshaft of a diesel engine (a rotor of the synchronous machine). Comparing the obtained data with the reference, the condition of bearings of synchronous machines, uniformity of its air gap, windings of the electric machine are also estimated. Now the level of the development of microprocessor techniques and the software allows to perform measurements of the specified parameters with high accuracy and with a short time interval.

The block diagram of measurements of spectral-power characteristics of the output voltage and current is given in Fig. 6. The diesel engine 2 results in the rotation of the synchronous generator 1 . The voltage of the synchronous generator acts in a ship three-phase network 440/254 V. The current and its instantaneous value in phases of the generator are supervised by means of current sensors 3 and 4, using Hall magneto-electric effect. The voltage from the current sensors acts on correction device 5 and on the alarm processor 7 . 


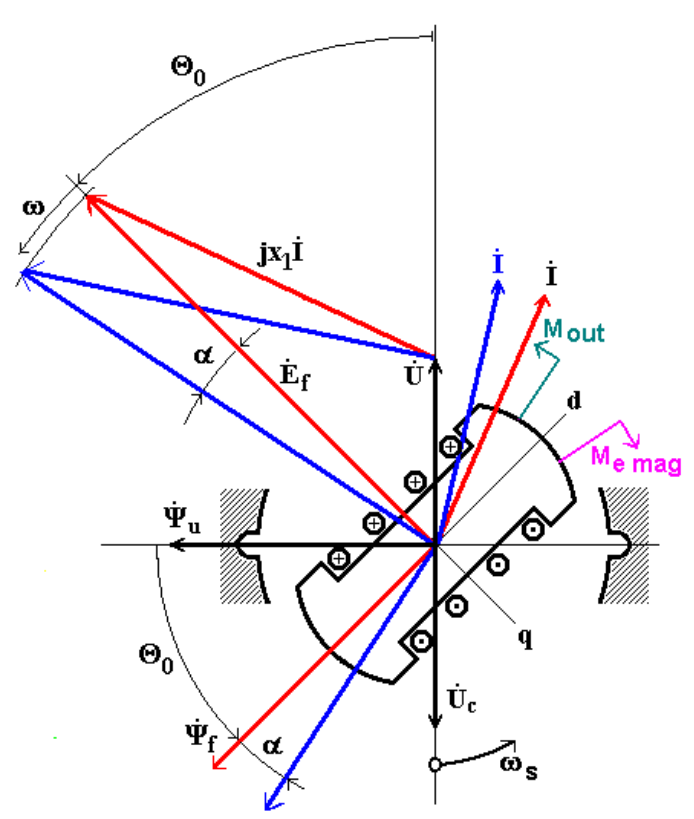

Fig. 5. Vvector diagrams of the synchronous machine.

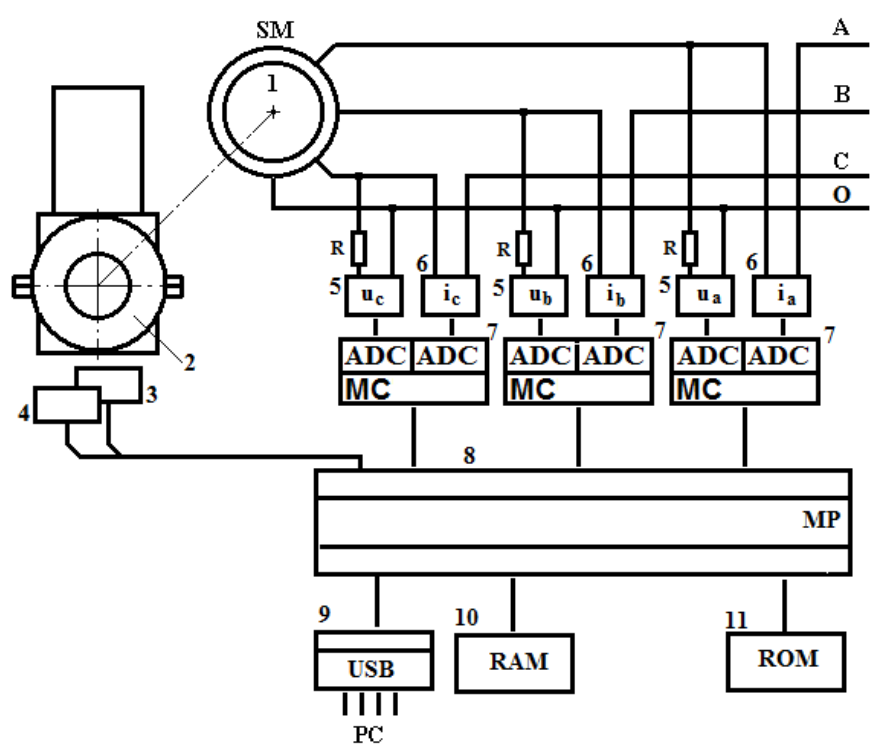

Fig. 6. Block-diagram of measurement diagnostic parameters for the diesel engine installation.

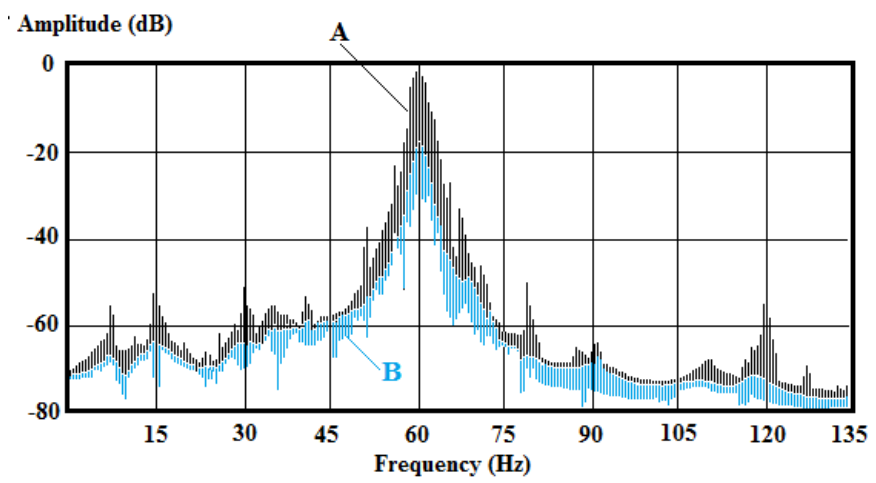

Fig. 7. Frequency spectrum of the stator current of the generator. A-spectrum of the diesel -generator with disturbances of the cylinder-piston group parameters; B-spectrum is a standard of the diesel-generator voltage
Fig. 6 illustrates the block-diagram of the diagnostic dieselgenerator installation. The sensors of the top dead point (TDP) of the first piston (sensor 3) and angular rotation frequency (sensor 4) are placed on its flywheel. Sensors 3 and 4 are of the same type having frequency output. Sensor 4 is placed above the tooth row of the crankshaft flywheel. The flywheel is provided with a magnet sign for sensor. The sensors of the phase voltage and currents 5 and 6 have a uniform amplitudefrequency characteristic. They are also applied for the galvanic isolation of the powerful circuits and measurements. They are realized on the IC ACS712 (Allegro Microsystems, frequency $80 \mathrm{kHz}$, voltage is up to $2 \mathrm{kV}$, input current - up to $30 \mathrm{~A}$ ). Analogue signals of the instantaneous values of the current and voltage of each phase of the stator are supplied to micro controllers 7. Micro controllers (MC) have two analoguedigital converters (ADC) at each of their inputs. The input of one ADC is connected to the sensor of current 6 , the other - to the sensor of voltage 5 . The phase instantaneous power and angle of phase shift can be calculated by means of the micro controller. The information comes to the micro processor (MP) 8. The same way the signals come from sensors 3 and 4. The signals are stored in the micro processor memory. From the micro processor 8 the information goes to the micro controller 9 of PIC16F2458 type. It converts the obtained information in accordance with the USB standard. This channel is used for the connection with personal computer. By means of computer the synchronization of all processes is carried out. Under the set program the obtained information is analyzed and the diesel engine installation is diagnosed. The obtained results of the measurements are analyzed and compared. Fig. 7 presents a frequency spectrum of the stator current of a ship's three-phase synchronous generator. The voltage of the generator is $440 \mathrm{~V}$, Frequency $60 \mathrm{~Hz}$, power $16 \mathrm{~kW}, \cos \varphi=0.8$, angular rotation frequency $94.19 \mathrm{rad} / \mathrm{sek}$ (900 rev/min). The number of poles is 8 . It is a 4-cycle and a 4-cylinder diesel engine; the cylinders are placed in series.

The highest interest in this spectrum is raised by so called typical frequencies. These frequencies are caused when the generator's main magnetic flux is modulated by changes of the instantaneous values of the angular frequency and acceleration of the diesel crankshaft, misalignment and rupture of the axes of the crankshaft and the shaft of generator, defects of the bearings, etc. With the help of this spectrogram the condition of the piston-cylinder group of the diesel can be determined in accordance with the amplitude of the typical frequencies in the range of $7.5 \mathrm{~Hz}, 15 \mathrm{~Hz}, 30 \mathrm{~Hz}$. The increasing of the amplitudes of theses frequencies (Fig.7.A), in comparison with reference frequencies in Fig.7.B, states the non-uniformity of the operation process in the pistons of the diesel (disturbance of the cyclic supply of fuel in time and volume), ageing of the pistons and cylinders, false operation of the piston-valve arrangement. 


\section{CONCLUSION}

The use of the synchronous machine in a diesel engine synchronous generator and compressor installations as a multipurpose diagnostic sensor is represented. By analyzing the received electric parameters of non-uniformity of the rotating torque, angular speed, angular acceleration and spectral-power structure of output currents and pressure and comparing them with reference values an theactual condition of systems and units both the piston machine and the synchronous machine can be estimated.

The increasing of the amplitudes of typical frequencies is signaling about the non-uniformity in the operation process of the diesel engine cylinders and its technical condition. The condition of the piston-cylinder group of the diesel can be determined in accordance with the amplitude of the subharmonics in the range of $7.5 \mathrm{~Hz}, 15 \mathrm{~Hz}, 30 \mathrm{~Hz}$.

\section{REFERENCES}

[1] V. T. Lamaris and D. T. Hountalas, "A general purpose diagnostic technique for marine diesel engines - Application on the main propulsion and auxiliary diesel units of a marine vessel," J. of Energy Conversion and Management, vol. 51, issue 4, 2010, pp. 740-753.

[2] J. Son et al. "Detecting the crankshaft torsional vibration of diesel engines for combustion related diagnosis," J. of Sound and Vibration, vol. 321, issues 3-5, 2009, pp. 1171-1185. http://dx.doi.org/10.1016/j.jsv.2008.10.024

[3] T. Lus, "Marine diesel engine diagnostics in operating conditions," Diagnostika - applied structural health usage and condition monitoring, 2(62), 2012 pp. 43-47.

[4] T. Lus, "Vibro-acoustic methods in marine diesel engines diagnostics," J. of KONES Powertrain and Transport, vol. 18, no. 3, 2011.

[5] A. F. Gogin, E. F. Kivalkin and A. A. Bogdanov, "Ship diesel engines (Bases of the theory, the device and operation)," M.: Transport, 1988. (in Russian).

[6] V. V. Lahanin, "Designing and calculation on durability of ship steam machines. River transport," 1955. (in Russian).

[7] A. I. Vazhnov, "Alternating current machinery in transient regimes," L.: Energy. 1980. (in Russian).

[8] A. Gasparjan, A. Terebkov and M. Terebkova, "The Use of Results of Spectral Analysis of Synchronous Generator Output Voltage for Technical Diagnostics," IEEE Int. Conf. Ind. Technology, ICIT 2006, 2006, pp. 2085-2090. http://dx.doi.org/10.1109/icit.2006.372566

[9] A. Gasparjans and A. Terebkovs, "Kuǵa enerǵetiskās iekārtas daudzfunkcionalā diagnostikas sistēma." "Multifunction Diagnostics System of Ship Power Installations," Rīgas tehniskās universitātes zinātniskie raksti. 4. sērija, Energétika un elektrotehnika. Rīga: RTU, 16. sējums, 2006, 163.-166. lpp. ISSN 1407-7345.

[10] J. Greivulis, A. Gasparian and A. Terebkov, "Complex diagnostic system of ship electrical machines," in Proc. Int. Conf. on Electric Ship, ELECSHIP 98, Istanbul, Turkey, Istanbul: Middle East Technical University Turkey, Sept. 1, 1998, pp. 56-58.

[11] Y. Greivulis, A. Gasparian and A. Terebkov, "Control Device of Electrical Machines Insulation Parameters of Ship Power Systems," Int. Aegean Conf. on Electrical Machines and Power Electronics, IEEE-Acemp 2001, Middle East Technical University. Turkey, Kusadasi, 27-29 June 2001, pp. 544-545. ISBN 975- 93410-0-X.
[12] A. Gasparjans and A. Terebkovs, "Kuga energetiskas iekartas daudzfunkcionala diagnostikas Sistema," "Multifunction Diagnostics System of Ship Power Installations," RTU 46. Starptautiska zinatniska konference. Riga, 13.-15. okt. 2005. ISSN 1407-7345.

[13] St. Polanowski and T. Lus, "Monitoring and diagnostic systems of marine diesel engines," 9th TC-10 IMECO Conference, Wroclaw, 1999, 9 p.

[14] J-C. Trigeassou, Electrical Machines Diagnosis, Wiley-ISTE. 2011. 334 p. http://dx.doi.org/10.1002/9781118601662

[15] C. Hui, W. Peili and Z. Jundong, "Modeling and Simulation of Working Process of Marine Diesel Engine with a Comprehensive Method," Int. J. of Computer Information Systems and Industrial Management Applications, vol. 5, 2013, pp. 480-487.

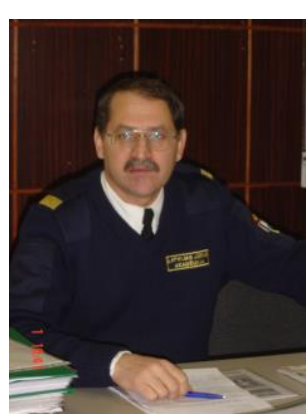

Aleksandrs Gasparjans is a Professor with the Latvian Maritime Academy. He graduated from the Riga Polytechnical Institute in 1970. He has the Qualification of Engineer in Electromechanics. He received the Doctor's degree in Engineering Science in 1992. His research fields are: ship power and reliability of electrical machines $y$, control and technical diagnostics, numerical magnetic field calculations in electrical machines. He has 117 scientific publications 117.

Address: 12/k-1 Flotes Str., Riga, LV-1016, Latvia.

Phone: +37167161124 .

E-mail: aleksandrs.gasparjans@latja.lv

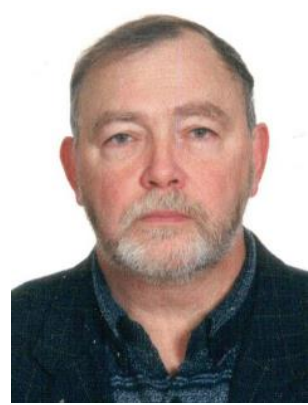

Aleksandrs Terebkovs, Dr. sc. ing., is an Associate Professor with the Latvian Maritime Academy. He received the Master degree from Riga Technical University in 1971, and the scientific degree of Doctor of Sciences in 2002. His scientific interests comprise technical diagnostics of power installations, electromagnetic compatibility, power supply sources. He has 111 scientific publications.

Address: 12/k-1 Flotes Str., Riga, LV-1016, Latvia.

Phone: +37167161124 .

E-mail: aleksandrs.terebkovs@latja.lv

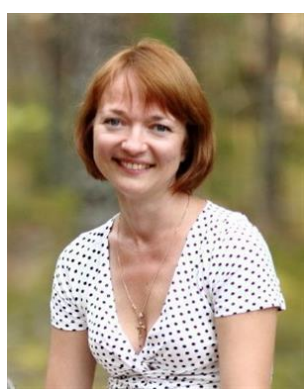

Anastasia Zhiravetska, Dr. sc. ing, received the $\mathrm{PhD}$ degree from Riga Technical University (RTU), Latvia, in 1999. Since 1999, she works at the Institute of Industrial Electronics and Electrical Engineering of RTU. She is a lecturer and runs practical classes for IEEI bachelor, master and post-graduate students. The fields of her scientific interests comprise power electronics, electric drives, motion control and application of modern technologies in translation, use of terminology in all these areas. She is participating in the development of different Latvian local and international projects.

Address: 12/1 Azenes Str. 12, Riga LV-1048, Latvia.

Phone: +37167089917

E-mail: zhiravecka@eef.rtu.lv 